\title{
IMPACT OF COVID-19 ON BORDER GUARDS TRAINING IN LATVIA, LITHUANIA, ESTONIA AND FINLAND
}

\author{
Mārtin̄š Spridzāns \\ State Border Guard College, Latvia \\ Jānis Dzerviniks \\ Rezekne Academy of Technologies, Latvia
}

\begin{abstract}
Due to Covid-19 the use of educational technologies, efficient and meaningful implementation of digital learning possibilities have become particularly important topics in order to develop border guards training. Issues related to training online, communication via several platforms, possibilities do develop interactive training content, need to use the potential of e-learning opportunities have become routine topics of discussion and ongoing research. Trainers of border guard training institutions have to tackle unexpected, unexplored, challenges and tasks related to border guards training due to Covid-19. Digital competence is particularly important to implement efficient online communication environment. To find out training and learning outcomes and define further necessities of e-learning development during emergency situations the authors of this research explore the scientific literature on the current research results, methodologies, approaches and best practices on developing e-learning systems in educational contexts during Covid-19. Survey results on attitudes, experiences and suggestions of border guards' trainers in Latvia, Lithuania, Estonia and Finland have been analysed to put forward suggestions for further border guard training development particularly in e-learning context during emergency situations.
\end{abstract}

Keywords: collaboration, development of digital competence, share of best practices.

\section{Introduction}

Spring of 2020 triggered new focus on transforming education and increasing educators' digital competence development both at civil and militarised training institutions since rapid shift from traditional face-to-face to online learning became inevitable process, essentially needed to continue the training process for border guards despite several restrictions. Efficient training of law enforcement officers, namely border guards, is the guarantee of our borders' safety and security. One of the key factors to reach successful outcome of border guards training is the integration of theory and practice to match daily job needs. Border guards as such and the training of border guards is in specific military training environment, hence particular attention to practical demonstration of skills demonstration is absolute requirement for carrying out 
Spridzāns \& Dzerviniks, 2021. Impact of Covid-19 on Border Guards Training in Latvia, Lithuania, Estonia and Finland.

future service duties. Due to specific training subjects such as weapon and shooting training, patrol tactics, document and vehicle examination it is not fully possible to reach learning outcomes and master the skills without face-to-face lessons.

Although there is a huge potential of using online communication platforms and learning management systems as Moodle, it has been concluded in several research findings and empirical observations that not all trainers are fully aware of online learning opportunities and are eager to develop interactive training content by using modern digital tools. Lack of practical experience in working with digital resources and conducting online lessons decrease efficiency of students' learning experiences and learning outcomes. The goal of this research is to identify the factors which facilitate or restrain the development of educator's digital competence and effective use of education technologies in border guards training process. To reach the goal of this research authors analyse scientific literature concerning education and technologies, summarize the success factors and drawbacks concerning border guards training during pandemic caused by Covid-19, based on scientific research findings and questionnaire results develop suggestions for improving the border guards training process.

\section{General Impact of Covid-19 on Education}

Covid-19 has restarted research trends concerning education and technologies interrelation, much effort has been put into analytical researches, collaboration projects to set future education strategies. Research carried out by UNESCO in 2020 identifies and outlines the problems due to the COVID-19 pandemic, it has been noted that many education systems responded by rapidly setting up remote learning systems to provide learning continuity, however they faced numerous challenges as students not having have access to the internet or certain devices, concerns related to safety and privacy online, teachers being unfamiliar with remote-learning solutions and finding difficulties in adjusting learning content to remote learning formats. Furthermore, the report outlines several drawbacks as uneven education-system decision making across administrative levels, budgetary issues, digital maturity, and operational capacities of education institutions (UNESCO, 2020).

The European Commission has developed the Digital Education Action Plan for 2021-2027 to promote digital education, transform Europe's education and training systems in a lifelong learning, share knowledge, good practices and experience and other important aspects concerning our daily activities in digital age. This plan includes deep analysis of the COVID-19 crisis on the quality of education concerning the access, infrastructure and educators' competences with regard to remote training processes. According to this plan an effective 
relationship between the use of digital technologies and learning outcomes depends on the following contextual and process-related variables:

1. Educators play a key role in adopting and using digital technologies for teaching, learning and student assessment in an effective way, fully online, remotely, or in a blended format thus educators need to have an appropriate level of digital competence and be able to recognise their potential for educational purposes.

2. The effectiveness of digital technologies for teaching and learning hinges on teacher practice and on how they integrate these tools into their teaching process.

3. Educators' perception of technologies as a learning tool are influenced by the organisational culture, which allows for different levels of autonomy or agency and shapes the way digital technologies are implemented and used for teaching and learning in a specific context.

4. The extent to which technology is deployed in purposeful and targeted ways.

Among other conclusions of Digital Education Action Plan it has highlighted the way we use computers and interact with our students. It has been concluded that, while using computers to look for information positively affects student achievement, the opposite occurs when computers replace face-to-face instruction time to practice skills. Researchers conclude that embedding digital technologies in teaching and learning processes is not only a simple replication or transposing face-to-face practices or traditional approaches online but instead it is a complex process requiring robust digital capacity, including planning for organisational change, ongoing monitoring and adaptation, and a strong focus on learning driven pedagogy, leadership, professional development, and a shared understanding and approach to using technology to support and enhance teaching and learning (European Commission, 2020). Digital Education Action Plan as well as several researchers (Ilomäki \& Lakkal, 2018) highlight the concept of digital capacity of educational institutions as progressively important success factor. This concept is interrelated to similar ones defined by literature. Researchers (Killen, Bentham, \& Knight, 2017) define organisational digital capability as the extent to which the culture, policies and infrastructure of an organisation enable and support digital practices.

Several research findings highlight the importance of meaningful integration of modern digital technologies in the educational process that will improve the quality and efficiency of learning and teaching in higher education, motivating students for learning and enabling them to acquire higher levels of competences. Researchers urge higher education teachers to continuously improve their digital competences for planning, delivering and assessing the educational process and communicating and interacting with students and peers (Čižmešija, Diković, 
Spridzāns \& Dzerviniks, 2021. Impact of Covid-19 on Border Guards Training in Latvia, Lithuania, Estonia and Finland.

Domović et al., 2018). According to conclusions of Daniela (2019) there is a need to prevent a centrifugal effect in technology enhance learning environment that can contribute to the fragmentation of the educational process, and further encourages to develop the principles of Smart Pedagogy to become the driving force for the technology enhance learning by setting priority to supplement teacher competence with predictive analytical competence. In the context of technology-led pedagogical transformations, Daniela defines SMART pedagogy as:

S - smart (in the sense of intellectual smartness), social

$\mathrm{M}$ - meta-cognitively developed and motivated

A - anywhere, anytime (in the sense of a learning process that is flowing across the temporal and spatial borders)

$\mathrm{R}$ - rapidly changing

$\mathrm{T}$ - technology enhanced, which considers the peculiarities of human development, the taxonomy of the educational process where the next generations are using the benefits of technology, and Smart Pedagogy bringing the students of the next generations in front of progress to serve as developers for new levels of innovation (Daniela, 2019).

According to Falloon (2020) technology-enhanced learning can be used for a variety of purposes to radically change the learning environment; however, educators are not always ready for these challenges. Similar conclusions can be found on a daily basis across all education sectors as well as in several research conclusions. Researchers suggest to increase the technological skills of all involved in education process to plan adequate pedagogical course related to remote teaching. In order to improve teachers' and learners' technological skills in relation to new emerging models and approaches encouraging the effective use of online learning systematic training and professional development activities should be provided. As the results of this challenges related to gaps in digital literacy in education among teachers, students and parents in various countries have been revealed. Researchers conclude that a precise plan should be developed, providing structured and planned educational material (content, methodologies and common goals) and more adequate e-learning platforms by using interactive suitable digital learning resources (Ferri, Grifoni\&Guzzo, 2020).

To tackle drawbacks of remote learning during Covid-19 there have been suggestions provided by UNESCO for structuring teacher schedules in order to reach better learning outcomes:

1. Teachers are advised to limit length of individual lessons and combine synchronous sessions with asynchronous activities (e.g., independent work followed max 30-45-minute live lesson) to avoid fatigue,

2. Teachers are encouraged to offer various learning experiences, and free up teachers' time to spend on other tasks, dedicate some time to 
teaching students how to use learning tools and platforms and explaining why they have been selected,

3. Flexibility in designing synchronous learning schedules (e.g., provide options to organize synchronous sessions outside of typical school hours if preferred for teacher and student population) are highly advisable.

4. Regular synchronous group activities focused on community building e.g., virtual clubs and social activities should be held, including regular face-to-face connection with students in order to assess well-being and barriers to engagement.

5. Finally, teachers are encouraged to participate in ongoing, frequent professional development that includes formal trainings (e.g., content delivery, training on tools) as well as informal opportunities to learn from peers as well as reserve blocks of time for lesson planning and curriculum development (UNESCO, 2020).

\section{Impact of Covid-19 on Border Guards Training}

State Border Guard College of the Republic of Latvia is the only education establishment for border guards in Latvia. Main goal of the College is to provide efficient formal and nonformal training for highly qualified border guards to ensure the inviolability of national and the EU external borders. To develop border guards e-learning systems the State Border Guard College of to the Republic of Latvia in collaboration with State Border Guard Service under the Ministry of the Interior of the Republic of Lithuania, Border and Coast Guard Academy of Finland and Estonian Academy of Security Sciences take part in Erasmus+ project "Strategic partnership for the improvement of e-learning systems in border guard training institutions 2018-1-LV01-KA202-047003”. In order to improve the elearning systems in border guards' education institutions and increase teachers' theoretical knowledge and practical skills in using modern e-learning tools the Partners explore, compare, analyse and summarize the best practices in planning and implementing e-learning systems for border guards training. Partners have carried out surveys on national needs analysis in e-learning context, results have been summarized in order to meet the actual needs of border guard training institutions with expected Project outcomes. The results of the needs analysis indicate common drawbacks as the lack of strategic approach to e-learning development and lack of teacher digital competence to develop interactive training content.

On the basis of Project goals, results of national needs and in order to successfully carry out Project development dissemination and sustainability 
Spridzāns \& Dzerviniks, 2021. Impact of Covid-19 on Border Guards Training in Latvia, Lithuania, Estonia and Finland.

activities Partners' e-learning systems SWOT analysis indicate the following concerns:

- There is a constant demand and common tendency to introduce e-learning systems, transform traditional study forms in e-learning environment, courses in border guard training institutions, however there is no strategic approach with regard to teachers' in-service training;

- $\quad$ Lecturers lack in-depth knowledge and motivation to develop e-study courses. The lecturers' view on design and implementation of e-learning in the learning process is different within the partner countries;

- $\quad$ Partner countries use the Moodle platform, but their versions vary, for example, interactivity elements need to be added to existing e-learning systems to have compatibility whilst sharing learning resources with one another;

- Teachers' responses in survey results indicate disbelief in e-learning advantages, more attention should be paid to analytical thinking development by showing best practice results from other countries

- IT professionals have a heavy workload in administering e-courses, therefore, in-service training in pedagogical field is needed, particularly to newcomers in border guard training institutions;

- The implementation of the project will enable the improvement of existing e-learning systems and make them more interactive, and the development of lecturers' qualifications will enable the development of e-learning processes in partner countries.

In order to develop e-learning systems for border guards partners have developed e-learning handbook containing guidelines in e-learning content development for border guards. The handbook includes include samples of best practices and instructions for efficient e-learning course development and implementation. Upon agreement of Partners unanimous decision was made to develop guidelines both available in Moodle content and printed version thus providing open access and ease of use for teachers and IT specialists. The content of the guidelines includes the following topics:

Topic 1: Planning of e-learning. This section includes theoretical and practical information on benefits of e-learning, tips on how to plan an effective and sustainable e-learning course for border guards. The aim of the topic is to increase the lecturers' knowledge about the possibilities on the potential of elearning in border guards training process, to guide the new lecturers in developing e-learning courses, to highlight the peculiarities of teacher - student, student - e-content interaction. Practical information is included on how to set elearning outcomes, what are the roles of parties involved in e-learning? 
Topic 2: Design and implementation of e-learning. This topic covers information on best practices in on the design stages of e-courses, the structure of the e-courses, user friendly navigation, visual attractiveness of the content, the interactivity elements and the grading and feedback.

Topic 3: Pedagogical tips on e-learning. This topic covers best practices that teachers should take into consideration when designing and delivering an elearning course e.g. how to transfer classroom materials into interactive content, how to communicate with students online, development interactive teaching aids e.g. in H5P module. The aim of the topic is to increase the knowledge of the lecturers about the possibilities of developing interactive teaching aids, transforming classroom materials for use in e-environment. The handbook includes development of samples and instructions for interactive content development particularly in Moodle platform.

The Project involves teacher digital competence development activities by organising several formal and informal activities. In order to increase border guard training institutions teachers' knowledge and skills in e-learning planning, design and implementation Partners have been implementing professional development activities in Partner countries explaining, demonstrating and sharing the best practices of interactive training content and successful delivery of online lectures.

\section{Data and Methodology}

To determine the factors that influence, decrease and increase e-learning systems capacities for border guards, scientific, pedagogical and psychological literature was analysed and evaluated, a survey of trainers was conducted, the data obtained was processed and analysed, interpretation and content analysis of the results obtained were performed.

To explore the existing situation in the field of Covid-19 impact on border guards training systems in Latvia, Lithuania, Estonia and Finland a study was conducted. Opinions of teachers were gathered and based on the findings, opportunities for raising and improving the efficiency of the organization of the training process were explored. The research method included setting research objectives, the selection of methods for data gathering, processing, analysis and interpretation of the data. The following research objectives were put forward:

- perform a survey to find out the impact of Covid-19 on border guards training during since March 2020 onwards;

- process and analyze the data obtained for improving the efficiency of border guards training, particularly in remote learning context in order to further develop e-learning systems for border guards. 
Spridzāns \& Dzerviniks, 2021. Impact of Covid-19 on Border Guards Training in Latvia, Lithuania, Estonia and Finland.

To ensure the validity of the data, teachers from all units involved in the fulfilment of the study processes were included in the study. The participants of the survey were teachers with the length of service in specific position was from 5 to 20 years. Mixed methods approach was used in data processing and analysis, which combines together quantitative and qualitative research strategies. To increase the reliability of the research results, data triangulation was used, obtaining and processing quantitative and qualitative data.

\section{Research Results}

To explore the existing situation, impact of Covid-19 on training process a survey of 44 teachers was conducted. To gathered the opinions of teachers survey from open questions was conducted and the respondents were given an opportunity to reflect their thoughts, attitudes, concerns and proposals related to border guards training process. A content analysis of the responses was performed with the aim to make conclusions and confirm the research results obtained theoretically and teacher survey about the existing situation related to Covid-19 impact on remote training process which helped to identify further development factors.

One of the key questions was to identify the level of teachers' digital competence which evidence the need to further conduct competence building activities. According to survey results $43 \%$ of the teachers when working with Moodle consider themselves as explorers who can add resources and build basic tests, $25 \%$ consider themselves to be beginners i.e. understanding basic functions and the rest of teachers consider themselves as the experts who can build advanced tests, modify settings, restrictions, tags, competences.

A positive aspect was drawn that the dominant part of teachers (78\%) consider that since beginning of Covid-19 their Moodle competence has increased and they have had the opportunity (94\% respondents) to increase their distant learning competence since Covid-19 started (working with Moodle, conducting online lessons). As a positive moment they mentioned the fact that due to Erasmus+ project they have access to materials (instructions) how to work with Moodle and conduct online lessons. Most of the teachers also agree that currently there are more opportunities to increase my digital competence (working with Moodle) than it was before Covid-19 started (79\% of respondents in total). Not all teachers (12\% only) consider the distant learning process their institution has been implemented successfully and $43 \%$ responded neutrally responded to this question which causes discussion and study what improvements are further needed. Similarly, their responses varied on the question whether they are able to carry out distance learning process efficiently - 50\% respondents consider themselves to be efficient remote trainers but $12 \%$ believe their colleagues are not 
able to carry out distance learning process efficiently. In total 86\% consider their institution currently to be more efficient in distant learning process due to Covid19 . When answering the question on learning outcomes $75 \%$ believe that distance learning outcomes are not so effective as face to face learning outcomes. Although most of respondents (87\%) have done online lectures in Zoom, Webex and other online platforms only $49 \%$ responded that they feel comfortable during online lessons. As the reason they don't feel comfortable during online lessons they consider psychological concerns as feeling of isolation, unusual students' behaviour online (unwillingness to use cameras, lack of interaction, connection problems) etc - 50\%, concerns about their IT competence in using Zoom, Webex etc. - 25\% (discomfort, lack of experience in videoconferencing applications and Moodle). $25 \%$ believe face to face communication to be more effective than online.

Surprisingly there were no equal agreement whether online communication between students and teachers allow to reach better learning outcomes and there was absolutely equal share of percentage in between strong agreement or strong disagreement which evidence the fact that teachers have no research-based conclusions what type of communication increases learning outcomes. Teachers also mention (42\%) that most of the time students spend learning individually with computer, online lectures are not often implemented which provides us with the room for discussion of what is the efficiency percentage between studentcentred and teacher-led model of remote training. Another evidence that there is dominantly classic dialogue built and teacher centred lectures carried out since only $18 \%$ of teachers during online lessons divide students in online working groups, in pairs, namely use breakout rooms function in Zoom or Webex. 97\% of teachers believe they must have good pedagogical skills to conduct efficient online lessons and only $68 \%$ believe they have these skills. When answering whether they think that institution's management adequately organized distance learning process in Spring 2020 responses divided. At rate of $43 \%$ respondents a strongly agree and $12 \%$ disagree that management adequately supported them. Providing comments what was not so well-organized during distance learning process and what would respondents to be improved the following responses were provided by teachers:

- $\quad$ Still there is some scepticism on e-learning, especially when it comes to the subjects, those that are by nature practical skills orientated ones.

- $\quad$ Teachers and students need to get clear instructions on how to use one or another tool, a kind of online seminar about the platform or tool they are going to use during online classes.

- $\quad$ There was no common concept of remote learning, no standard for all.

- Administration is reluctant to support teachers. Students can watch hundred moves with boxing matches, but they will not learn how to fight 
Spridzāns \& Dzerviniks, 2021. Impact of Covid-19 on Border Guards Training in Latvia, Lithuania, Estonia and Finland.

after all. What about shooting skills, physical activities? Working with data bases? They need practice, and we need to see their reaction immediately.

- Faster management involvement in the technical field was required (provision of equipment, stable internet connection, etc.)

- $\quad$ There was not enough good cooperation with commanders of training companies. There is a need to rethink the mechanism for motivating teaching staff to develop and integrate interactive learning material into Moodle. Specific requirements (which should be developed), evaluation criteria (if not available) and types of awarding should be defined (stipulating that only teachers whose material is considered to be of high quality and useful, as well as positively evaluated) will be awarded.

As seen from responses teacher motivation system has to be revisited. Also when answering to motivational factors $80 \%$ of teachers believe that those who create interactive learning content in Moodle should be positively motivated by managers e.g. extra bonuses, rewards etc, $75 \%$ think teachers who cannot create interactive learning content in Moodle should be strongly influenced by managers to update their digital competence. As to the biggest motivators for development $56,3 \%$ state that they would develop their digital competence if there was a positive encouragement from management and $37,5 \%$ if there was feedback provided from students.

\section{Conclusion}

Based on scientific literature analysis and teacher survey conducted as the positive moment caused by Covid-19 pandemic across all education sectors is the increase of digital competence development opportunities for teachers. Highest concerns highlight low involvement of teachers whilst communicating online, disbalance of independent learning and online learning as well as the need to increase digital capacity of education institutions.

In order to further develop border guards training systems in Latvia, Estonia, Lithuania and Finland based on scientific literature research, analysis of Erasmus strategic partnership project outcomes and teachers survey authors of this research put forward the following suggestions:

1. In order to develop border guards training systems, particularly in remote training contexts, digital capacity in terms of technologies i.e. laptops, tablets, stable WI-FI coverage both for trainers and cadets should be put as one of priorities to further develop efficient e-learning environment. 
2. Survey results disclose the need to continue the development of teachers' digital competence which should take place on a regular basis both at local and at international contexts such as Erasmus+ strategic partnerships or mobility visits and other formal, non-formal and informal teacher digital capacity development activities. Particular attention during teacher digital competence development activities should be focused on pedagogy and technology interaction and integration aspects in order to continue access to highly interactive and meaningful training content as well as provide efficient online collaboration opportunities.

3. Regular student feedback and support in interactive content development is needed in order to analyse positive and negative aspects of remote training. Graduate students should be involved in interactive content development, piloting and evaluation.

4. Specific mechanism for motivating teaching staff to develop and integrate interactive learning material into Moodle should be developed followed by adequate evaluation and supervision process, individual approach to each teacher to investigate factors influencing digital competence development. Specific requirements and evaluation criteria of interactive training content should be developed.

\section{Acknowledgements}

This research was performed within ERASMUS+ Programme KA2 Strategic partnership project No. 2018-1-LV01-KA202-047003 "Strategic partnership for the improvement of elearning systems in border guard training institutions" and Transformative Digital Learning in Doctoral Program of Pedagogical Science in Latvia (DocTDLL) lzp-2018/2-0180 projects.

\section{References}

Čižmešija, A. Diković, M., Domović, V. (2018). Handbook for teaching competence enhancement in higher education, Co-funded by the Erasmus + Programme of the European Union. Ministry of Science and Education of Croatien, ISBN: 978-953-810321-6, 2018.

Daniela, L. (2019). Didactics of Smart Pedagogy. Smart Pedagogy for Technology Enhanced Learning. Springer.

Falloon, G. (2020). From digital literacy to digital competence: the teacher digital competency (TDC) framework. Education Tech Research Dev 68, 2449-2472 (2020). https://doi.org/10.1007/s11423-020-09767-4

Ferri, F., Grifoni, P., Guzzo, T., (2020). Concept Paper Online Learning and Emergency Remote Teaching: Opportunities and Challenges in Emergency Situations. Institute for Research on Population and Social Policies, National Research Council, 00185 Rome, Italy. 
Spridzāns \& Dzerviniks, 2021. Impact of Covid-19 on Border Guards Training in Latvia, Lithuania, Estonia and Finland.

Killen, C., Beetham, H., Knight, S. (2017). Developing organisational approaches to digital capability. Jisc guide. Retrieved from https://www.jisc.ac.uk/guides/developingorganisational-approaches-to-digital-capability

Ilomäki, L., Lakkala, M. (2018). Digital technology and practices for school improvement: innovative digital school model. RPTEL 13, 25 (2018). https://doi.org/10.1186/s41039018-0094-8

European Commission. (2019). The 2018 International Computer and Information Literacy Study (ICILS) Main findings and implications for education policies in Europe. doi:10. 10.2766/584279 https://ec.europa.eu/education/sites/default/files/document-librarydocs/icils-2018-policy-note.pdf

Digital Education Action Plan. (2020). for (2021-2027). Resetting education and training for the digital age. Retrieved from: https:/ec.europa.eu/education/education-in-theeu/digital-education-action-plan_en

UNESCO. (2020). COVID -19 response - remote learning strategy. Remote learning strategy as a key element in ensuring continued learning. Retrieved from https://en.unesco.org/sites/default/files/unesco-covid-19-response-toolkit-remotelearning-strategy.pdf

UNESCO. (2020). Digital Pedagogies for Teaching and Learning, UNESCO MGIEP, 35 Ferozshah Road, New Delhi-110001. https://mgiep.unesco.org/digital-teacher-training 